\title{
PERUBAHAN FASADE RUMAH DI PERUMAHAN WONINGPARK GERGAJI SEMARANG
}

\author{
Burhan Arif *) \\ Program Studi Magister Teknik Arsitektur, Fakultas Teknik, Universitas Diponegoro, \\ Jl. Hayam Wuruk 5, Kampus Undip Pleburan, Semarang, Indonesia
}

\begin{abstract}
Abstrak
Arsitektur Indis merupakan asimilasi atau campuran dari unsur-unsur budaya Barat terutama Belanda dengan budaya Indonesia khususnya dari Jawa. Woningpark Gergadji (Taman Perumahan Gergadji atau NIS-Park) adalah kompleks perumahan yang dihuni oleh pegawai beserta keluarganya yang berkerja di NIS/ Nederlands Indische Spoorweg Maatschapij (kini PT. KAI DAOP IV) sejak masa Kolonial Belanda. Rumah-rumah di dalam perumahan tersebut masih terawat dan terpelihara. Namun kini tiap rumah tidak lagi memiliki tampilan fasad yang sama seperti tampilan fasad yang dahulu pada masa kolonial bahkan terlihat ada tambahan bangunan yang menyerupai rumah diantara rumah-rumah aslinya. Tesis ini membahas mengenai perubahan pada fasad rumah utama di Perumahan Woningpark Gergadji yang dilakukan penghuni sejak menempatinya. Jika fasad rumah terjadi perubahan yang tidak mengikuti aturan yang sesuai dengan arsitektur bangunan tersebut maka fasad bangunan akan kehilangan identitas. Fenomena yang berkembang pada rumah-rumah tersebut adalah perubahan yang terjadi pada fasad bangunan utama dan bertambahnya bangunan baru di dalam lahan rumah. Oleh karena itu, pihak PT. KAI DAOP IV serta penghuni rumah pada saat ini harus bekerjasama dengan baik agar perumahan tersebut tetap mempertahankan identitas arsitekturnya.
\end{abstract}

Kata kunci: perubahan fasad, arsitektur indis, motivasi penghuni

\begin{abstract}
[A Change of The Facade of a House in Recidential Woningpark Gergadji Semarang] Indis architecture is an assimilation or a mixture of elements of Western culture especially the Dutch with Indonesian culture, especially from Java. Woningpark Gergadji (Park Housing Gergadji or NIS Park) is a residential complex that is occupied by employees and their families who work in the NIS / Nederlands Indische Spoorweg Maatschapij (now PT. KAI DAOP IV) since the Dutch colonial era. The houses in the housing preserved and maintained. But now every home no longer has the same view of the facade as the first appearance of the facade of the colonial period look even additional buildings that resemble a home between homes - the original home. This thesis discusses a changes the facade of the main house at Recidential Woningpark Gergadji performed by residents since occupied. If there is a change of the facade that does not follow the rules that match the architecture of the building, it will make the facades of the building will lose its identity. A growing phenomenon in that houses, there is a change in the facade of the main building and the new building increased in the land. Therefore, the PT. KAI DAOP IV and residents today must work well together so that the houses retaining the architectural identity.
\end{abstract}

Keywords: a change of facade, Indis architecture, tenant motivation

\section{Pendahuluan}

Arsitektur Belanda yang menghiasi Kota-kota Besar di Indonesia diawali pada masa abad 16 hingga tahun 1940-an, ketika berkembangnya aliran arsitektur seperti Art Nouveau, Amsterdam School, De Stijl, serta Niuwe Bouwen yang berurutan mempengaruhi

\footnotetext{
${ }^{*}$ Penulis Korespondensi.

E-mail: han.papillonstudio@gmail.com
}

desain para arsitek Belanda sehingga pada masa Hindia Belanda tercipta bangunan Arsitektur Indis (Handinoto, 1996). Arsitektur Indis merupakan asimilasi atau campuran dari unsur-unsur budaya Barat terutama Belanda dengan budaya Indonesia khususnya dari Jawa (Suptandar, 2001). Hal tersebut dapat dilihat dari bentuk bangunan, material yang digunakan, hingga tata ruang dalamnya. Woningpark Gergadji (Taman Perumahan Gergadji atau NIS-Park) 
adalah kompleks perumahan yang dihuni oleh pegawai beserta keluarganya yang bekerja di NIS/ Nederlands Indische Spoorweg Maatschapij (kini PT. KAI DAOP IV) sejak masa Kolonial Belanda. Pada tahun 1914 NIS menggunakan lahan milik Haminte yang berada di lahan sawah lembah Gergadji seluas $61.580 \mathrm{~m}^{2}$. Sistem sewa lahan tersebut dibayar tiap tahunnya sebesar $£ 4.500$ (empat ribu lima ratus golden) dengan batas sewa selama 75 tahun (Tillema, 1922).

Dalam penelitian bangunan arsitektur Indis pada rumah di Perumahan Woningpark Gergadji, Fasad rumah Indis yang masih asli menjadi perhatian khusus bagi peneliti. "Fasad menyampaikan keadaan budaya saat bangunan itu dibangun, fasad mengungkap kriteria tatanan dan penataan, dan berjasa memberikan kemungkinan dan kreativitas dalam ornamentasi dan dekorasi" (Krier, 1988). Tujuannya untuk mengetahui bagaimana perubahan itu terjadi serta mengetahui bagaimana perlakuan penghuni rumah terhadap bangunan rumah yang dihuninya pada saat ini. Fenomena yang berkembang pada rumahrumah tersebut adalah perubahan yang terjadi pada fasad bangunan utama dan bertambahnya bangunan dengan berbagai fungsi seperti teras, garasi, paviliun, kamar kos, warung.

Dari fenomena tersebut di atas menjadi alasan peneliti untuk melakukan penelitian lebih dalam mengenai perubahan fasad rumah di Perumahan Woningpark Gergaji di Kota Semarang.

\section{Permasalahan}

1. Rumah-rumah di Perumahan Woningpark Gergadji merupakan bangunan Indis yang kini telah mengalami perubahan fasad menyebabkan rumahrumah tersebut kehilangan identitas Indis-nya.

2. Banyak bangunan baru menggunakan lahan atau halaman depan dari rumah asli (rumah induk) menyebabkan fasad rumah tampak: lebar, sempit, dan tidak terlihat karena tertutup bangunan baru.

\section{Rumusan Permasalahan}

Berdasarkan latar belakang di atas, maka dalam penelitian mengenai Perubahan Fasad Rumah di Perumahan Woningpark Gergaji Semarang akan dilakukan pembatasan permasalahan. Sehingga dalam perumusan permasalahan akan menekankan pada, apakah perubahan fasad rumah Indis di masa kini mempengaruhi arsitektur rumah Indis tersebut.

\section{Metode Penelitian}

Pendekatan dalam melakukan penelitian ini menggunakan pendekatan kualitatif. Penelitian kualitatif adalah suatu pendekatan yang juga disebut pendekatan investigasi dengan cara mengumpulkan data langsung bertatap muka dan berinteraksi dengan orang-orang di tempat penelitian (McMillan \& Schumacher, 2001). Penelitian kualitatif juga bisa dimaksudkan sebagai jenis penelitian yang temuantemuannya tidak diperoleh melalui prosedur statistik atau bentuk hitungan lainnya (Strauss \& Corbin, 2003). Kaitannya dengan objek penelitian yang diambil adalah perubahan fasad rumah bangunan Indis peneliti perlu memperoleh data secara mendalam dengan observasi lapangan dan wawancara agar temuan-temuan data di lapangan dapat membantu saat proses analisa penelitian. Oleh karena itu, untuk mencari tahu perubahan Fasad bangunan Rumah Indis di Perumahan Woningpark Gergadji, peneliti menggunakan metode kualitatif.

Pengumpulan data dan informasi melalui studi observasi lapangan, data dokumentasi dan wawancara dari pihak PT. KAI Bagian Pengelolaan Aset DAOP IV dan pihak penghuni rumah, serta studi literatur.

\section{Hasil dan Pembahasan}

Sejumlah 70 fasad rumah Indis bentuk fasadnya dibedakan berdasarkan kelas dan tipe rumah. Dari perbedaannya ditemukan ciri yang sama pada elemen fasad. Untuk mengetahui ciri rumah Indis secara umum dapat diketahui dari beberapa cara yaitu; ruang dalam dengan plafon tinggi dan dapat dilihat dari fasad depan yang menunjukkan ketinggian lantai dengan atap (Sumalyo, 1993), bentuk tiang atau kepala tiang (Soekiman, 2000), Umumnya rumah Indis beragam hias sederhana kecuali rumah orang Cina yang kaya (Soekiman, 2000), gable/gevel merupakan bentuk segitiga yang mengikuti bentuk atap (Soemalyo, 2003), serta penggunaan flat roof, tower, dan bentuk kubus (Tjahjono, 1998).

Kemudian ciri rumah Indis di atas tersebut dianalisis pada Perumahan Woningpark Gergadji, dan hasilnya adalah :

a. Atap (Gambar 1 dan 2):

- Memiliki kemiringan atap lebih dari 30\% dengan bentuk yang bermacam-macam.

- Elemen atap, pada bangunan rumah di perumahan Woningpark Gergadji lebih sederhana, yang sangat menonjol yaitu Gevel/Gable pada bagian kemuncak atapnya berbentuk huruf $\mathrm{X}$ dengan bentuk segitiga sebagai lubang angin di bagian atap, serta Deltis (konsol penyangga atap tritisan).

- Bentuk atap arah hadapnya bervariasi, sesuai dengan rancangan tipe (kelas) bangunan rumah.

b. Dinding (Gambar 3 dan 4):

- Memiliki tembok tebal, menggunakan pasangan 1 bata atau sekitar $25 \mathrm{~cm}$.

- Kolom/ tiang pada serambi/ emperan tidak ada pada tiap rumah di perumahan Woningpark Gergadji.

- Hiasan dinding berupa pasangan bata yang menonjol dengan posisi membujur (horizontal) pada fasad. Disusun dengan warna yang berbeda dengan warna dindingnya. Misalnya: hitam, coklat (merah bata). 

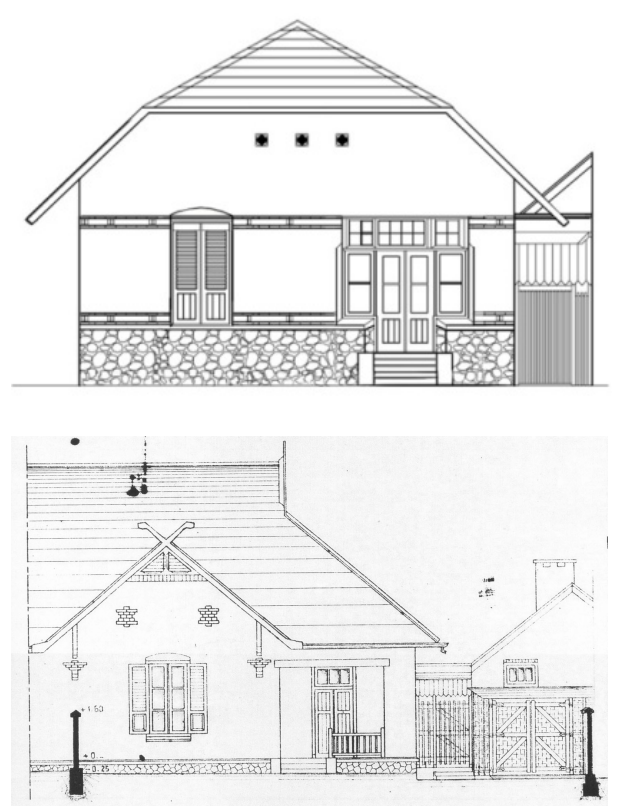

Gambar 1. Macam bentuk atap rumah di Perumahan Woningpark Gergadji (Dokumentasi Peneliti, 2011)
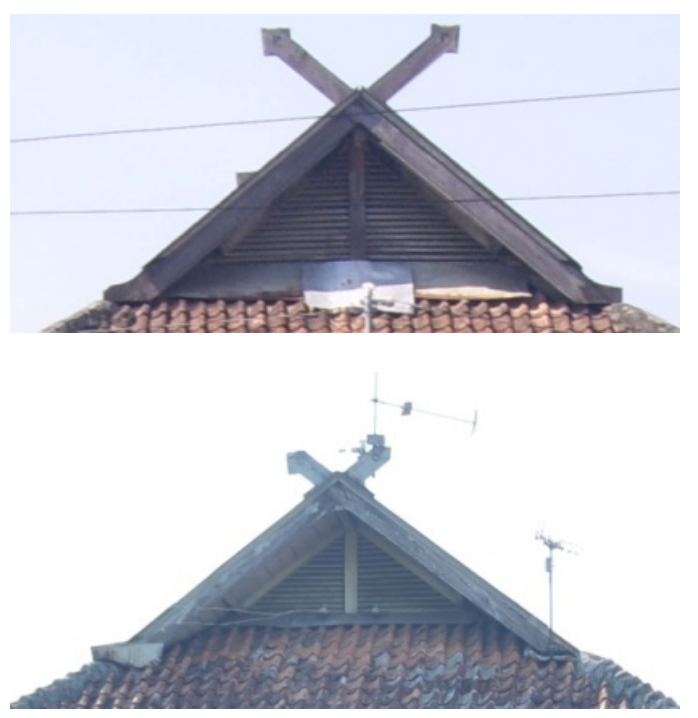

Gambar 2. Ornamen atap rumah di Perumahan Woningpark Gergadji (Dokumentasi Peneliti, 2012)

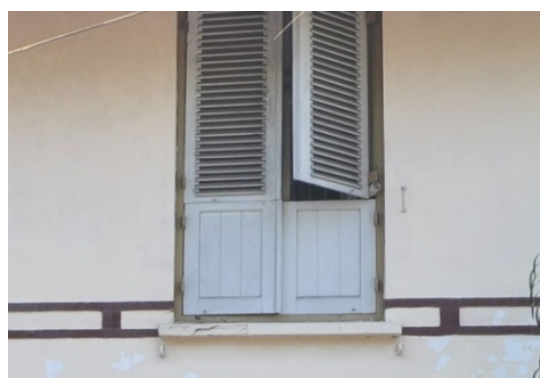

Gambar 3. Macam hiasan dinding garis pada fasad rumah di Perumahan Woningpark Gergadji

(Dokumentasi Peneliti, 2012)
- Hiasan dinding lain berupa bentuk kotak-kotak pada bagian atas pintu utama fasad rumah.

- Terdapat lubang angin (bouvenlicht), di atas jendela kamar pada bagian fasad.

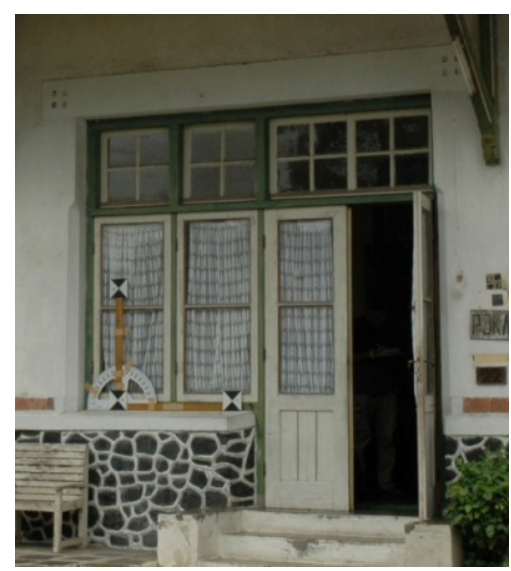

Gambar 4. Macam hiasan dinding kotak pada fasad rumah di Perumahan Woningpark Gergadji

(Dokumentasi Peneliti, 2012)

c. Pintu dan jendela

- Ukuran pintu dan jendela lebar dan tinggi.

- Pintu utama adalah pintu ganda dengan panel kaca.
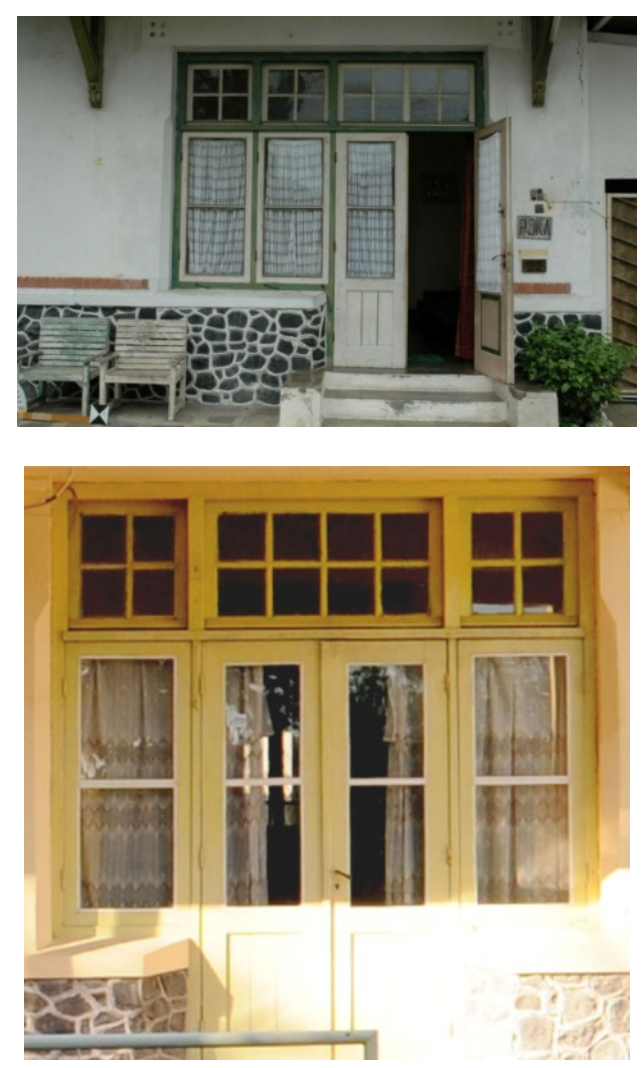

Gambar 5. Macam bentuk pintu dan jendela utama rumah di Perumahan Woningpark Gergadji (Dokumentasi Peneliti, 2012) 
- Pada jendela biasanya terdapat ornamen dan hiasan artdeco. Namun pada rumah Indis di perumahan Woningpark Gergadji lebih sederhana tanpa ornamen hanya dibuat jendela panel.

- Jendela kamar memiliki bukaan ganda ke luar dan ke dalam.

- Jendela kamar sisi bukaan ke luar menggunakan jendela krepyak dan sisi dalam menggunakan jendela kaca.

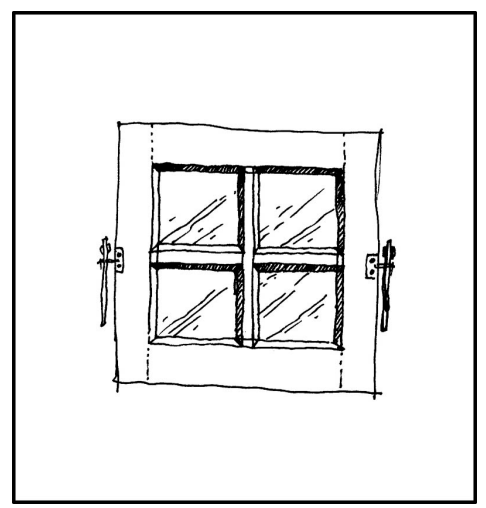

Gambar 6. Sketsa jendela atas pada pintu dan jendela fasad rumah di Perumahan Woningpark Gergadji (Dokumentasi Peneliti, 2012)
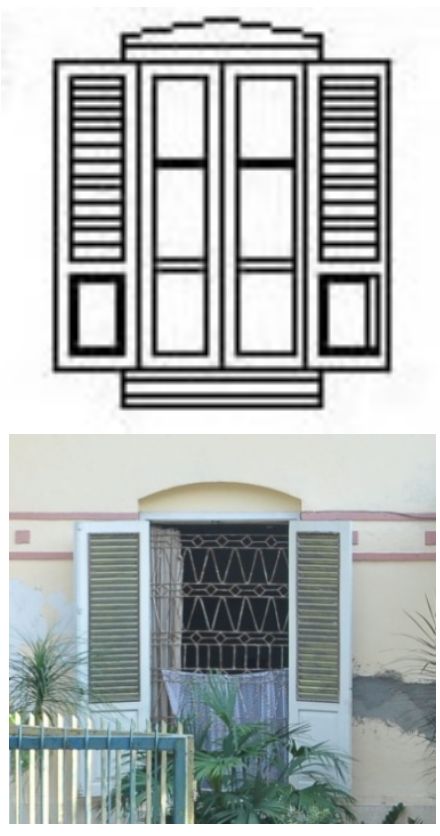

Gambar 7. Sketsa dan foto dari jendela kamar fasad rumah di Perumahan Woningpark Gergadji

(Dokumentasi Peneliti, 2012)

d. Lantai

- Lantai dalam rumah menggunakan tegel ukuran 20x20.

- Tidak ada ornamen/corak pada tegelnya.

- Memiliki perbedaan level dari halaman luar ke dalam rumah.
- Memiliki tangga kecil tiap depan pintu masuk utama.

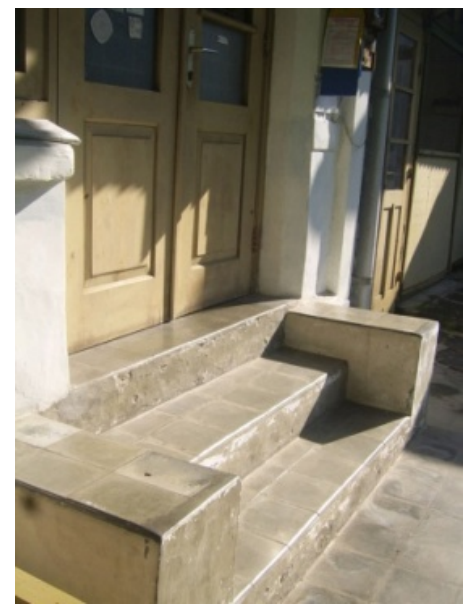

Gambar 8. Tangga kecil pada pintu masuk rumah utama di Perumahan Woningpark Gergadji (Dokumentasi Peneliti, 2012)

- Pada halaman depan rumah, terdapat batu kotak yang disusun untuk jalan setapak.

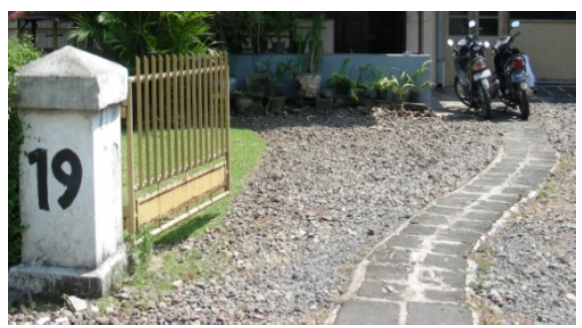

Gambar 9. Jalan setapak dari batu kotak di halaman depan rumah di Perumahan Woningpark Gergadji (Dokumentasi Peneliti, 2012)

\section{Kajian Perubahan \& Motivasi Perubahan}

Michel Beer (2000:452) mengatakan bahwa berubah adalah memilih tindakan yang berbeda dari sebelumnya, perbedaan itulah yang menghasilkan suatu perubahan. Menurut Potts dan LaMarsh (2004:36) perubahan merupakan pergeseran dari keadaan sekarang suatu organisasi menuju keadaan yang diinginkan di masa depan. Perubahan tersebut dilihat dari segi proses dan manusianya. Berikut ini beberapa jenis perubahan bentuk (Ching, 1994:64) yaitu: Perubahan Dimensi, Substractive (perubahan akibat pengurangan), Additive (perubahan akibat penambahan), Perubahan bentuk dan gaya dalam arsitektur, sering didahului dengan perubahan sosial yang terjadi dalam masyarakatnya (Sigfried Gideon 1941:4)

Perubahan dipengaruhi oleh motivasi seseorang atau sekelompok orang. Tindakan merubah sebuah rumah merupakan hal yang umum dilakukan oleh penghuninya ketika status sosial ekonomi, dan atau sosial budayanya mengalami perubahan yang lebih baik (Weber, 1968:8). Soemanto (1987) secara umum 
mendefinisikan motivasi sebagai suatu perubahan tenaga yang ditandai oleh dorongan efektif dan reaksireaksi pencapaian tujuan. Maslow (2006) mengemukakan bahwa kebutuhan kita terdiri dari lima kategori yaitu: Fisiologis (seperti: tidur, makan, minum), keselamatan atau keamanan, rasa memiliki atau sosial, penghargaan, dan aktualisasi diri.

\section{Kajian Rumah Dinas}

Rumah Dinas merupakan rumah yang digunakan untuk pegawai dan keluarganya sementara waktu selama bekerja dalam suatu perusahaan. Definisi dari rumah negara dapat dilihat dalam Peraturan Pemerintah Nomor 40 Tahun 1994 tentang Rumah Negara, adalah Bangunan yang dimiliki negara dan berfungsi sebagai tempat tinggal atau hunian dan sarana pembinaan keluarga serta menunjang pelaksanaan tugas Pejabat dan/atau Pegawai Negeri.

Analisa perbandingan perubahan fasad rumah dikelompokkan menurut 4 elemen pembentuk fasad, yaitu : Atap (jenis dan ornamen), Dinding (material dan ornamen), Pintu dan Jendela (jenis dan ornamen), Lantai (material dan ornamen). Setelah dilakukan pengelompokkan maka ditemukan beberapa ketidaksesuaian dan beberapa kesamaan dari wawancara dengan penghuni dalam melakukan perubahan-perubahan yang berkait dengan fasad rumah.

\section{Atap}

- Atap rumah utama tidak dirubah, karena apabila penghuni merubah bentuk atap, maka tampilan fasadnya akan terlihat sekali berubah.

- Penambahan atap kanopi rumah menurut penghuni sangat dibutuhkan karena dapat mengurangi panas dan air hujan yang masuk ke dalam ruang tamu.

- Penggantian atap teras dengan bentuk modern membuat tampilan rumah lebih nyaman dilihat karena penghuni berharap untuk menghilangkan kesan kuno dan kumuh.

\section{Dinding}

- Penambahan bangunan, atap, dinding, kusen pintu \& jendela tidak menyesuaikan dengan bentuk fasad rumah aslinya karena penghuni merasa itu hanya bangunan penunjang. Namun penghuni tidak sampai memperhatikan jika ada bangunan baru yang menempel pada dinding fasad rumah utama dapat merubah tampilan fasadnya. Terlihat dari beberapa rumah dengan bangunan tambahan dibuat sejajar dengan dinding fasad.

- Perubahan ornamen dinding juga dilakukan oleh beberapa penghuni rumah, seperti memberi warna cat yang sama dengan dinding, tertutup oleh kanopi/ atap teras. Terdapat penambahan ornamen atau garis-garis pada dinding bangunan tambahan yang tidak sama dengan ornamen dari bangunan fasad utama. Sepertinya bangunan tambahan tersebut untuk menunjukkan tampilan berbeda pada fasad rumahnya. Namun penghuni tidak menyadari bahwa ornamen tambahan telah membuat tampak fasad berubah.

\section{Pintu dan Jendela}

- Penambahan pintu dan jendela utama pada fasad rumah pernah dilakukan pada beberapa rumah saat masih masa pembangunan. Dapat dilihat dari gambar fasad rumah yang didapatkan oleh peneliti, ada fasad rumah yang tidak ada pintu dan jendela. Sedangkan gambar fasad rumah lainnya sudah ada pintu dan jendela yang sesuai dengan fasad. Namun penghuni tidak mengetahui bahwa pintu dan jendela pernah ditambahkan pada fasad rumahnya.

- Penambahan pintu dan jendela pada bangunan tambahan tidak ada usaha menyesuaikan bentuk dari pintu dan jendela utama. Hal tersebut dilakukan penghuni karena menurutnya bangunan tambahan itu bersifat sementara atau tidak selamanya akan berdiri berdampingan dengan rumah utamanya. Jadi jika suatu kali semua bangunan tambahan dirobohkan sangat mungkin sekali.

\section{Lantai}

- Penambahan atau perubahan lantai pada halaman depan rumah dilakukan oleh beberapa rumah seperti: plester semen, paving block, dll. alasannya agar mobil dapat parkir tanpa merusak halamannya. Secara tampilan tidak terlalu terlihat, namun jika terjadi hujan lebat maka bagian halaman dapat terjadi genangan air yang menyebabkan tampilan rumah terlihat kurang baik.

- Perubahan lantai atau penggantian material lantai pada teras yaitu seperti tegel diganti dengan keramik, dilakukan oleh beberapa rumah di perumahan tersebut. Tujuannya agar tampilan rumah terlihat enak dipandang dari luar. Namun penghuni tidak mempertimbangkan mengenai perubahan untuk ketinggian lantai, pilihan warna material yang terlalu mencolok, bahkan pada kolom sebagian juga di finishing keramik. Hal tersebut dapat merubah tampilan fasad asli rumah.

Hasil dari analisa perubahan fasad rumah di Perumahan Woningpark Gergadji Semarang dapat disimpulkan dan dirangkum kembali dalam 3 (tiga) hal temuan yang menjadi tujuan dari penelitian di atas. Penjelasan untuk tiga temuan dari hasil penelitian adalah :

a. Tipologi awal fasad rumah Indis pada Perumahan Woningpark Gergadji dipengaruhi oleh periode masa yang berbeda. Rumah-rumah tiap kelas dibangun secara bertahap, maka dapat ditarik kesimpulan bahwa rumah yang dirancang berbeda-beda tipe menurut kelasnya, memiliki komposisi yang tidak selalu konsisten karena 
dalam perkembangan arsitektur Indis juga terdapat penyesuaian dengan periode dan trend yang sedang terjadi. Tiap fasad memiliki perubahan mengikuti bidang tipe fasad dan lahan yang ada. Meskipun tipe rumahnya berbeda namun antara rumah tipe Single dan Couple memiliki ciri perubahan yang serupa.

b. Perubahan fasad pada rumah-rumah di Perumahan Woningpark memiliki pola mengikuti bentuk atap, tipe rumah, dan ketersediaan halaman depannya. Dari analisa peneliti menemukan bahwa hal tersebut dipengaruhi oleh: Perubahan iklim di Kota Semarang yang semakin panas, kebutuhan ekonomi, serta keamanan dan kenyamanan untuk dihuni.

- Perubahan fasad yang dipengaruhi oleh perubahan iklim di Kota Semarang terlihat pada penambahan atap teras untuk mengurangi sinar matahari yang langsung menerpa dinding fasad. Karena bentuk gevel atap rumah yang tinggi bagian dinding fasad selalu terkena sinar matahari yang masuk ke ruang dalam, serta ketika hujan turun sampai membasahi ruang dalam. Penambahan elemen pintu dan jendela pada ruang tamu kini yang awalnya adalah teras/serambi terbuka tanpa pintu dan jendela adalah salah satu dampak dari perubahan iklim.

- Perubahan fasad yang dipengaruhi oleh kebutuhan ekonomi terlihat pada rumah $\mathrm{J}$. Jogja No.20 adalah salah satu rumah dengan pernambahan dinding pada fasad rumah sebagai ruang kamar kos serta tambahan bangunan permanen berupa kamar kos untuk disewakan agar dapat menambah penghasilan dan membayar sewa rumah tersebut. Dan hal tersebut juga dilakukan pada beberapa rumah lain dengan luasan yang berbeda.

- Perubahan fasad yang dipengaruhi oleh keamanan dan kenyamanan penghuni rumah dapat dilihat dari berubahnya pagar tanaman menjadi pagar besi, atau tembok bata. Beberapa diantaranya masih mempertahankan pagar tanamannya karena penghuni merasa lebih nyaman dengan hijau-hijauan disekeliling rumahnya, namun pada sisi samping rumah selalu terdapat bangunan baru atau dinding permanen yang tertutup rapat hingga ke belakang rumah. Dengan cara seperti itu dapat mempengaruhi kenyamanan penghuninya juga. Selain membuat dinding permanen, rumah-rumah di Perumahan Woningpark juga melakukan perubahan pada fasad agar tampilannya terlihat berbeda, diantaranya dengan mengganti warna dinding, menutup ornamen seperti pada rumah Jl. Kedungdjati No.14, menambah material baru yang sedang tren pada periode tertentu, dll.
- Temuan lain dari penelitian adalah perubahan fasad juga dipengaruhi oleh perubahan fungsi pada beberapa fasad rumah seperti rumah $\mathrm{Jl}$. Solo No.17 dan No.11a. Rumah di J1. Solo No.17 pada sisi jendela utama ruang kamar kini berubah fungsi menjadi pintu utama rumah karena ditempati oleh penghuni lain. Jadi dalam satu rumah induk ditempati oleh dua keluarga (rumah tangga)/ lebih dengan mengambil garis tengah dari rumah tersebut, sehingga komposisi fasad rumah menjadi berubah dan tampilan fasadnya menjadi tidak harmonis.

c. Aspek utama yang membuat fasad rumah di Perumahan Woningpark Gergadji berubah adalah karena perumahan tersebut tidak memiliki masterplan yang matang sebagai kemungkinan perkembangan jaman. Hal tersebut terlihat dari beberapa tipe rumah yang sama tidak konsisten dalam rancangannya. Mengingat rumah tersebut adalah rumah dinas yang kini rata-rata ditinggali oleh pensiunan PT. KAI atau keluarga dari pensiunan PT. KAI yang merasa telah banyak melakukan maintenance (perawatan dan perbaikan) pada rumah yang dihuninya sehingga penghuni merasa berhak untuk mengelola secara pribadi aset yang dimiliki PT. KAI tersebut.

\section{Kesimpulan}

Berikut ini kesimpulan dari temuan yang sebelumnya sudah dijabarkan, yaitu:

a. Dari hasil temuan tipologi awal fasad rumah menunjukkan arsitektur rumah Indis pada masa itu juga mengalami perkembangan dan penyesuaian berdasarkan iklim yang terjadi pada kota Semarang sehingga sudah seharusnya dalam melakukan perubahan pada rumah, iklim dapat dijadikan acuan yang penting agar penambahan baru tidak sekedar memberikan tampilan baru (modern) saja.

b. Peraturan yang jelas untuk IMB pada lahan perumahan serta pengawasan yang ketat dari pihak PT.KAI dapat dijadikan acuan agar perubahan dengan alasan apapun dapat terkendali dan terarah dengan baik.

c. Aspek utama yang telah dijelaskan dari analisa penelitian dapat menjadi pertimbangan bagi PT. KAI agar Perumahan Woningpark Gergadji dapat menjadi perumahan yang memiliki nilai sejarah arsitektur Indis yang masih bertahan meskipun periode dan jaman berubah.

\section{Ucapan Terima Kasih}

Terima kasih disampaikan kepada Bp. Prof. Ir. Totok Roesmanto M,Eng, Bp. Ir. Agung Budi Sardjono MT selaku dosen pembimbing, Direktur PT. KAI DAOP IV, Ibu Ratri, Ibu Budiastuti, Bp. Eko, Ibu Benowo, serta Ibu Dwiyono selaku narasumber yang tinggal di Perumahan Woningpark Gergadji, serta pihak-pihak yang bersedia meluangkan waktunya 
untuk membantu memberikan informasi \& data penting, sehingga tercapainya sebuah tesis yang baik.

\section{Daftar Pustaka}

Beer, Michael. (2002). Breaking The Code of Change. USA: President and Fellow of Harvard College.

Ching, Francis DK. (1994). Architechture, Form, Space and Order. Jakarta: PT. GELORA AKSARA PRATAMA.

Handinoto. (1996). Perkembangan Kota dan Arsitektur Kolonial Belanda di Surabaya 18701940. Diterbitkan atas Kerja Sama Lembaga Penelitian dan Pengabdian Kepada Masyarakat Universitas Kristen Petra Surabaya dan Penerbit Andi. Yogyakarta: Andi Offset.

Maslow, Abraham. (2006). On Dominace, Self Esteen and Self Actualization. Ann Kaplan: Maurice Basset.

McMillan, J. H., \& Schumacher, S. (2001). Research in education: A conceptual introduction (5th ed.). New York: Longman.

Krier, Rob. (2001). Architectural Compotition. London: Academy Edition.

Soekiman, Djoko. (2000). Kebudayaan Indis dan Gaya Hidup Masyarakat Pendukungnya di Jawa (Abad XVIII-Medio Abad XX). Yogyakarta: Bentang.
Soemanto, Wasty. (1987). Psikologi Pendidikan. Jakarta: Bina Aksara.

Strauss, Anselm \& Corbin, Juliet. (2003). DasarDasar Penelitian Kualitatif. Yogyakarta: PustakaPelajar.

Sumalyo, Yulianto. (1993). Arsitektur Kolonial Belanda Di Indonesia. Yogyakarta: Gadjah Mada University Press.

Sumalyo, Yulianto. (2003). Arsitektur Klasik Eropa. Yogyakarta: Gadjah Mada University Press.

Suptandar, J.Pamudji. (2001). Arsitektur "Indis" Tinggal Kenangan. Harian Kompas. (http://arsitekturindis.wordpress.com/2001/10/1 4/arsitektur-indis-tinggal-kenangan/).

Potts, Rebecca and LaMarsh, Jeanne. (2004). Managing for Success. London : Duncan Baird Publishers.

Tillema H.F. (1922). Kromoblanda. Over't vraagstuk van het Wonen in Kromo's groote land. Vijfde deel, tweede stuk.

Tjahjono, R. (1998). Studi Karakteristik Arsitektural Pada Hunian Masyarakat Berbahasa Madura di Malang Selatan (Studi Kasus: Desa Ganjaran, Gondanglegi). Laporan Penelitian. Tidak dipublikasikan. Malang: Jurusan Arsitektur Universitas Brawijaya. 